\title{
Applicability of logistic regression with sum-to-zero constraint parameterization in risk assessment for parotid malignancy
}

Shari Messinger Cayetano ( $\nabla$ smessinger@biostat.med.miami.edu )

University of Miami School of Medicine

Kaming Lo

PPD https://orcid.org/0000-0002-8897-1818

Christopher Fundakowski

Temple University

Zoukaa Sargi

University of Miami School of Medicine

Research article

Keywords: logistic regression, risk assessment, parotid malignancy

Posted Date: May 4th, 2020

DOI: https://doi.org/10.21203/rs.2.16732/v2

License: (1) This work is licensed under a Creative Commons Attribution 4.0 International License.

Read Full License 
The authors have withdrawn this preprint from Research Square 